\title{
Tailoring Characteristics of PEDOT:PSS Coated on Glass and Plastics by Ultrasonic Substrate Vibration Post Treatment
}

\author{
Nadia Gholampour ${ }^{1}$, Dominikus Brian ${ }^{1}$ and Morteza Eslamian ${ }^{1,2, *(D)}$ \\ 1 University of Michigan-Shanghai Jiao Tong University Joint Institute, 800 Dongchuan Road, \\ Shanghai 200240, China; nadiagholampour@sjtu.edu.cn (N.G.); dominikusbrian@sjtu.edu.cn (D.B.) \\ 2 State Key Lab for Composite Materials, School of Materials Science and Engineering, Shanghai Jiao Tong \\ University, 800 Dongchuan Road, Shanghai 200240, China \\ * Correspondence: Morteza.Eslamian@sjtu.edu.cn or Morteza.Eslamian@gmail.com
}

Received: 13 August 2018; Accepted: 21 September 2018; Published: 24 September 2018

\begin{abstract}
In this work, we excited as-spun wet films of PEDOT:PSS by ultrasonic vibration with varying frequency and power. This is a low-cost and facile technique for tailoring the structural and surface characteristics of solution-processed thin films and coatings. We deposited the coatings on both rigid and flexible substrates and performed various characterization techniques, such as atomic force microscopy (AFM), scanning electronic microscopy (SEM), X-ray photoelectron spectroscopy (XPS), attenuated total reflection-Fourier transform infrared spectroscopy (ATR-FTIR), transmittance, electrical conductivity, and contact angle measurements, to understand how the ultrasonic vibration affects the coating properties. We found that as a result of ultrasonic vibration, PEDOT:PSS sheet conductivity increases up to five-fold, contact angle of water on PEDOT:PSS increases up to three-fold, and PEDOT:PSS roughness on glass substrates substantially decreases. Our results affirm that ultrasonic vibration can favor phase separation of PEDOT and PSS and rearrangement of PEDOT-rich charge transferring grains. In addition to providing a systematic study on the effect of ultrasonic frequency and power on the film properties, this work also proves that the ultrasonic vibration is a novel method to manipulate and tailor a wide range of properties of solution-processed thin films, such as compactness, chain length and arrangement of polymer molecules, conductivity, and surface wettability. This ultrasonication method can serve organic, printed and flexible electronics.
\end{abstract}

Keywords: organic thin films; organic coatings; conducting polymers; ultrasonic vibration; PEDOT:PSS; flexible substrates

\section{Introduction}

The importance of thin films and coatings in numerous micro- and nano-scale devices, such as emerging thin films solar cells, sensors and actuators, transistors, organic light-emitting diodes, displays, and thermoelectric devices, has made them a central interdisciplinary topic [1]. For such devices, development of low-cost, flexible and solution-processed conducting thin films is of prime importance [2-4]. Poly(3,4-ethylenedioxythiophene) (PEDOT): poly(4-styrenesulfonate) (PSS) or PEDOT:PSS is a good candidate, which can be used in the form of a hole transporting layer, as well as transparent electrode [5-12]. Improved flexibility, reduced weight and solution-process-ability are some of the key advantages of PEDOT:PSS over conventional conducting transparent oxides [13-15].

PEDOT:PSS is formed of PEDOT, which is a positively charged conducting polymer, but insoluble in water, entangled in negatively charged PSS chains, which is a nonconductive polymer, but helps dispersion and stabilization of PEDOT in water. In an aqueous solution, PEDOT:PSS forms a micelle structure, because the hydrophobic PEDOT stays away from water molecules in a core surrounded 
by a thin hydrophilic PSS-rich surface layer [11]. For the same composition or brand of PEDOT:PSS precursor solution from the same manufacturer, variations in deposition and post-treatment steps may alter the arrangement and engagement of its two ingredients [16-22], affecting the electronic and optical characteristics of the ensuing film [16-21,23-25]. Thus, it is imperative to understand how PEDOT and PSS behave or interact in a particular system. In addition, since the electrical conductivity of pristine PEDOT:PSS is low due to the insulating PSS moiety, and the demand for PEDOT:PSS thin films with higher conductivity is on the rise, it is desired to develop ideas and methods to increase the conductivity. In this regard, much effort has been devoted through adding various additives such as high boiling points solvents and polar compounds [12,26-30], organic and inorganic salts [30,31], surfactants [32,33], ionic liquid [34-37], and sulfuric and formic acids [38,39]. For instance, polar solvents with high dielectric, such as dimethyl solfuxide (DMSO) [26] or ethylene glycol (EG) [29], can considerably enhance the conductivity of PEDOT:PSS by weakening the electrostatic forces between PEDOT and PSS, facilitating charge transfer.

Although the aforementioned chemical methods can improve the conductivity of PEDOT:PSS films, a facile, low-cost, and environmentally friendly mechanical technique is more appealing. In this context, Eslamian and coworkers [40-44] demonstrated remarkable improvement in almost all characteristics of PEDOT:PSS thin films by imposing ultrasonic vibration on the substrate and the wet film during or after the deposition process by spin or spray coating. In the case of spray-on PEDOT:PSS films [40] and PEDOT:PSS/graphene composite films [45,46], it was observed that employing ultrasonic vibration promotes solution mixing and film surface levelling, due to a mild instability caused by the vibration $[45,46]$, resulting in a more uniform and conductive PEDOT:PSS thin film. An excessive power of vibration, on other hand, resulted in breakup of the PEDOT:PSS film [44]. In the case of spun films [41], it was observed that the ultrasonic vibration of the wet film, for a few seconds, imposed immediately after spinning, results in phase segregation in the film, an effect that has been reported in chemical methods, as well. This is due to the interaction of acoustic waves with the wet film that causes micromixing and local heating in the film, as illustrated in Figure 1a [47]. Eslamian [47] also reviewed conventional and emerging applications of ultrasonic vibration in various configurations and systems. The aforementioned works [40-44] were performed with a single frequency of $40 \mathrm{kHz}$ on films coated on glass substrates. Owing to the potential of the method, in this work, we carefully characterized the response of the ultrasonic transducers and systematically investigated the effect of varying ultrasonic vibration frequency and power on characteristics of spun PEDOT:PSS thin films, to gain further insight and also obtain optimum conditions from a practical point of view. Moreover, in this work, we systematically investigated the potential of the application of the method on plastic substrates, briefly studied in [48], owing to their importance for commercialization purposes.

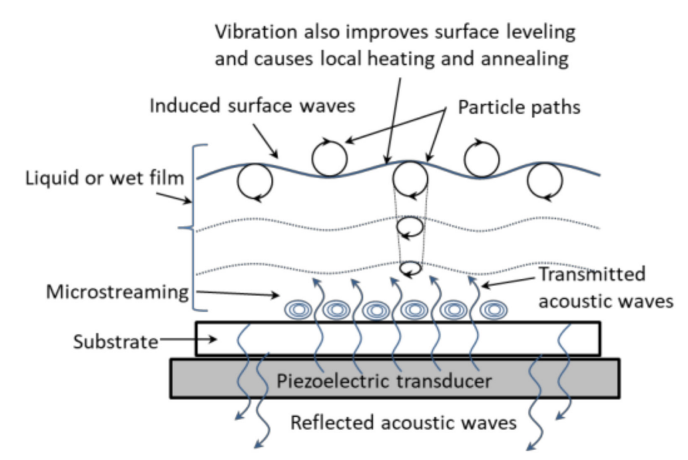

(a)

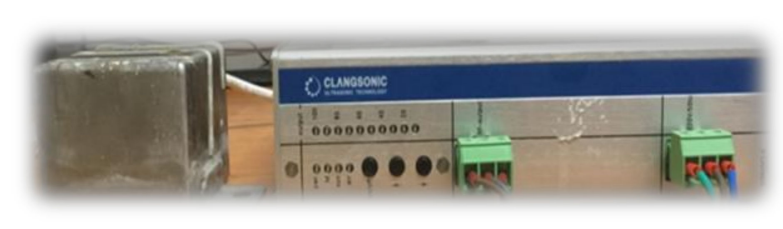

(b)

Figure 1. Schematic of ultrasonic excitation of a wet film. (a) Theoretical considerations and (b) a signal generator (right) and a vibrating box/substrate holder (left) used in the experiments. A Langevin transducer with a given frequency was welded to the inside of the top surface of the box, generating vibrations perpendicular to the film. Part (a) was adapted with permission from [47]. Copyright 2017 Elsevier. 


\section{Materials and Methods}

\subsection{Experimental}

PEDOT:PSS aqueous solution (Clevious PH 1000) was purchased from Shanghai Kingtech Chemicals Co., Ltd., Shanghai, China, and sieved with a $0.45 \mu \mathrm{m}$ filter before use. Indium-doped tin oxide (ITO)-coated glass substrates $(20 \mathrm{~mm} \times 20 \mathrm{~mm})$ with a sheet resistance of $8 \Omega$ /sq were purchased from AGC Co., Ltd., Qinhuangdao, Hebei, China. ITO-coated PET (polyethylene terephthalate) substrates $(20 \mathrm{~mm} \times 20 \mathrm{~mm})$ with sheet resistance of $9.8 \Omega$ /sq were purchased from OIKE \& Co., Ltd., Kyoto, Japan. The glass/ITO substrates were washed in an ultrasonic bath with deionized water, isopropyl alcohol and acetone, sequentially for $15 \mathrm{~min}$, followed by cleaning in an ultraviolet (UV) cleaner for $15 \mathrm{~min}$. The PET/ITO substrates were more delicate, and thus cleaned differently, i.e., first with a mixture of isopropyl alcohol and acetone (1:1 vol.\%) in an ultrasonic bath, and then in a UV cleaner for $5 \mathrm{~min}$. Before cleaning, with the exception of samples prepared for transmittance tests, we glued the PET/ITO substrates on bare glass substrates, in order to facilitate film deposition, handling, and characterization.

The PEDOT:PSS solution was spun at $2500 \mathrm{rpm}$ for $25 \mathrm{~s}$. For the samples subjected to the ultrasonic substrate vibration post treatment (SVPT) for $10 \mathrm{~s}$, the as-prepared wet spun films were immediately placed and taped on an ultrasonically vibrating steel box at intended frequency and power (Figure 1b). Then the pristine and SVPT films were annealed on a hotplate at $120{ }^{\circ} \mathrm{C}$ for $20 \mathrm{~min}$ and $15 \mathrm{~min}$ for glass/ITO and PET/ITO substrates, respectively. Inside the vibrating steel boxes with a top dimension of $\sim 80 \mathrm{~mm} \times 80 \mathrm{~mm}$, disk-type Langevin ultrasonic transducers at 20, 40, or $68 \mathrm{kHz}$ were mounted, transferring vertical ultrasonic vibrations to the top surface of the steel box and then to the substrate and wet films. The transducers were actuated by signal generators (Yuhuan Clangsonic Ultrasonic Co., Ltd., Taizhou, Zhejiang, China).

\subsection{Characterizations}

We used a 3D scanning vibrometer (PSV-500-V, Polytec, Irvine, CA, USA) to find the vibrational response of the ultrasonic transducers on the surface of the steel boxes. The Z-axis scanning head was placed $60 \mathrm{~cm}$ above and perpendicular to the box surface. A HeNe laser with wavelength of $633 \mathrm{~nm}$ was directed to three different points on the vibrating box surface. Data were simultaneously acquired and processed by the signal processor of the vibrometer. Prior to starting the experiments, the ground noise was characterized. A preliminary sweep from 0 to a desired frequency $+5 \mathrm{kHz}$ was carried out for each experimental run. A vibrational profile scanning with duration of several seconds was then carried out for a range of frequencies to find the resonant peaks.

We measured the sheet resistance of PEDOT:PSS films using the four-point probe technique with a Keithley 2450 source meter (Keithley Instruments, LLC, Cleaveland, OH, USA). For each case, we prepared and characterized three samples, where the probes were applied on the four corners of the $20 \mathrm{~mm} \times$ $20 \mathrm{~mm}$ films. We measured the film thickness by a KLA-Tencor P7 surface profilometer (Milpitas, CA, USA). For each case, we prepared three samples and performed three measurements on each sample. The film morphology and roughness were obtained by an atomic force microscope (AFM, Nano Navi E. Sweep, Seiko Instruments, Chiba, Japan). Roughness values were reported as the root of mean squares (RMS). We obtained high magnification surface topography images, using a field-effect scanning electron microscope (FE-SEM, Zeiss Ultra Plus, Carl Zeiss AG, Oberkochen, Germany). We measured the contact angles of PEDOT:PSS droplets on ITO-coated substrates and also contact angles of water on the prepared PEDOT:PSS films with a Theta-Lite, Biolin Scientific, Espoo, Finland, at three different points on each substrate. We measured the temperature of the wet films and surface temperature of dry substrates and the vibrating steel box with an infrared thermometer (FLIR, Tallinn, Estonia). We obtained the transmittance with a UV-Vis-NIR spectrophotometer (lambda 750 s, Perkin Elmer, Waltham, MA, USA). The binding energy of sulphur in the PEDOT:PSS film was analysed using X-ray photoelectron spectroscopy (XPS) on a ESCALAB 250 X-ray photoelectron spectrometer (Thermo Fisher Scientific, Waltham, MA, USA), with 
an X-ray penetration depth of few $\mathrm{nm}$. Attenuated total reflection-Fourier transform infrared spectroscopy (ATR-FTIR, Perkin Elmer, Waltham, MA, USA) spectra were recorded using a Spectrum 100, Perkin Elmer device. We performed all tests at least in triplicate, to reduce the uncertainty of the data.

\section{Results and Discussion}

We start the results with presenting the vibrational characterization of the steel boxes equipped with ultrasonic transducers. Later we will show that how varying vibration frequency and power will affect the characteristics of PEDOT:PSS coatings. We first measured the environmental noise profiles swept from 0 to $80 \mathrm{kHz}$, as shown in Figure S1 in the supporting information. No noticeable peaks or dynamics were detected in frequencies higher than $105 \mathrm{~Hz}$, verifying that background noise does not affect our $\mathrm{kHz}$ transducers. Figure 2a,b, respectively, show the Z-axis vibrational profiles associated with transducers with factory-specified nominal or resonance frequency of 20 and $40 \mathrm{kHz}$. Multiple peaks are detected, but the maximum amplitudes occur at 18.48 and $41.20 \mathrm{kHz}$, respectively. This is a slight deviation from the nominal frequencies. The loci of the peaks are repeated at three transducer input powers of 5, 25, and $50 \mathrm{~W}$, corroborating the repeatability and reliability of the data. As expected, the maximum vibrational amplitude of the transducers increases with an increase in the transducer power. The transducer with a nominal frequency of $68 \mathrm{kHz}$ shows a bimodal behavior with two regimes of dynamic peaks between $40-50 \mathrm{kHz}$ and around the nominal frequency of $68 \mathrm{kHz}$ with smaller amplitude (Figure 2c). Since we drive this transducer with a signal generator at $68 \mathrm{kHz}$, the first mode is irrelevant here and does not occur in our thin film experiments.

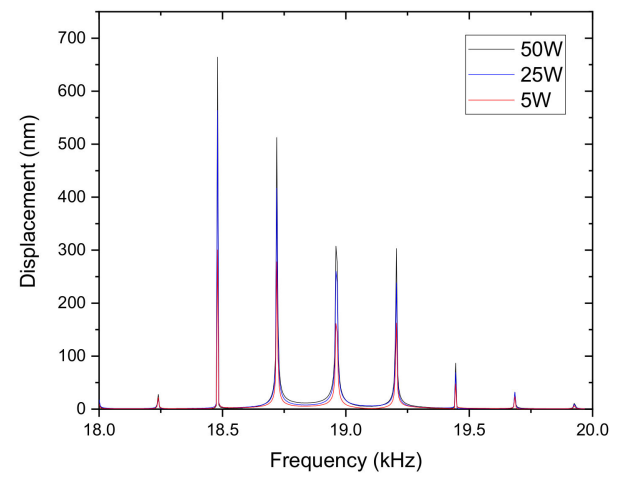

(a)

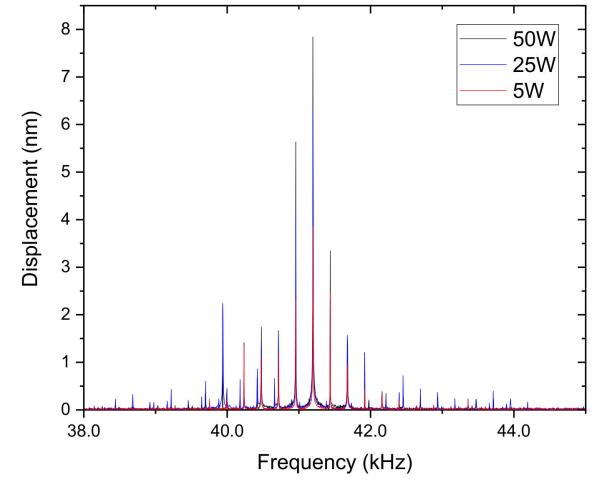

(b)

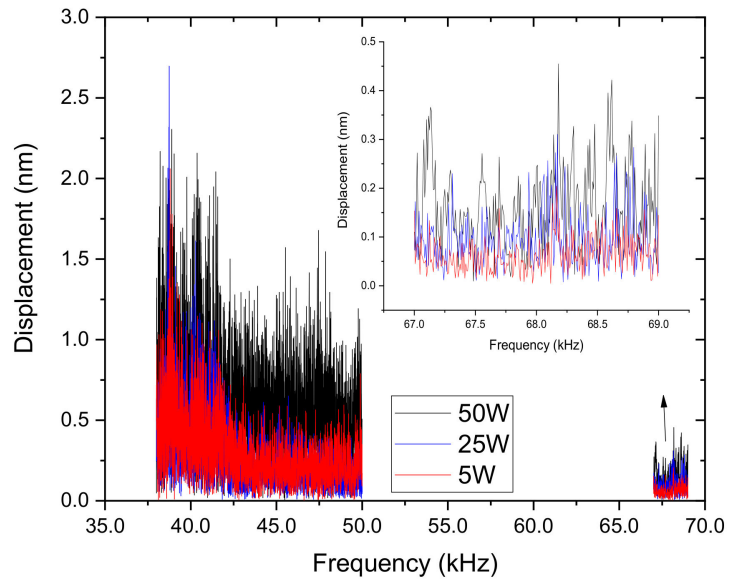

(c)

Figure 2. Vibrational response measured on the surface of the steel boxes with transducer nominal frequency of (a) $20 \mathrm{kHz}$, (b) $40 \mathrm{kHz}$, and (c) $68 \mathrm{kHz}$, under different input powers of 5, 25, and $50 \mathrm{~W}$. The inset in (c) shows the magnified signals around $70 \mathrm{kHz}$. 
In Table 1, we have listed the maximum vertical displacement of the surface of the steel boxes (amplitude of vibration). At $20 \mathrm{kHz}$, the amplitude varies from 300 up to $664 \mathrm{~nm}$, when the input power increases from 5 to $50 \mathrm{~W}$. At $40 \mathrm{kHz}$, the amplitude rises from 3.85 to $7.84 \mathrm{~nm}$, when the input power increases from 5 to $50 \mathrm{~W}$. The amplitude of vibration of the $68 \mathrm{kHz}$ transducer is in the Angstrom range, for the relevant mode near this resonance frequency. It is evident that the amplitude decreases with frequency and increases with power. If we assume the transducer generates a sinusoidal vibration in the form $d=d_{\max } \sin \omega t$ (for a mass-spring system), $d$ being the displacement, $d_{\max }$ the amplitude or maximum displacement, $\omega$ the frequency and $t$ the time, the total energy of the system is obtained as $U=1 / 2 m \omega^{2} d_{\text {max }}^{2}, m$ being the mass of the system. The input power of the transducer is related to this energy, and therefore proportional to $\omega^{2} d_{\max }^{2}$. At a fixed frequency and mass of the system, one would expect that, for instance, when the power increases from 5 to $50 \mathrm{~W}$ (ten-fold), the maximum displacement, $d_{\max }$, would increase $\sqrt{10}$-fold ( three-fold). The results of Table 1 , however, show about a two-fold increase in $d_{\max }$ for 20 and $40 \mathrm{kHz}$ transducers. There is an impedance mismatch between the top surface of the transducer and the top side of the steel box, and a fraction of the vibrational energy transmits to the top side of the steel box. The rest of the acoustic energy either transmits to the air or is reflected and converted to heat in the transducer body. In this example, it appears that about $1 / 3$ of the energy of the transducer has reflected and damped. Now, we consider a case where the input power or energy is fixed, and the frequency is doubled. The above equation for total energy predicts that the maximum displacement, $d_{\max }$, should decrease with a factor of two, i.e., a $d_{\max }$ of $300 \mathrm{~nm}$ at $20 \mathrm{kHz}$ and $5 \mathrm{~W}$, should become $150 \mathrm{~nm}$ at $40 \mathrm{kHz}$ and $5 \mathrm{~W}$. Table 1 , however, shows a $d_{\text {max }}$ of $3.85 \mathrm{~nm}$ for the latter case, much smaller than the expectation. We attribute this effect to the impedance mismatch between the transducer and metal box and its strong dependence on frequency. With an increase in frequency, the impedance mismatch increases and less acoustic energy can transmit to the steel box [49]. The data of Table 1 are imperative for correct interpretation of the results of the thin films.

Table 1. Maximum measured displacement (amplitude) $d_{\max }$ of all vibration frequencies under different powers $(5,25$, and $50 \mathrm{~W})$. We estimated the maximum displacement for $20 \mathrm{~W}$ by nonlinear interpolation.

\begin{tabular}{|c|c|c|}
\hline Nominal Frequency $(\mathbf{k H z})$ & Power (W) & $\begin{array}{c}d_{\max }(n m) @ \\
\text { Resonance Frequency }(\mathbf{k H z})\end{array}$ \\
\hline \multirow{4}{*}{20} & 5 & $300 @ 18.48$ \\
\hline & $20^{a}$ & $517 @ 18.48$ \\
\hline & 25 & $563 @ 18.48$ \\
\hline & 50 & $664 @ 18.48$ \\
\hline \multirow{4}{*}{40} & 5 & $3.85 @ 41.20$ \\
\hline & $20^{a}$ & $5.78 @ 41.20$ \\
\hline & 25 & $6.40 @ 41.20$ \\
\hline & 50 & $7.84 @ 41.20$ \\
\hline \multirow{8}{*}{68} & 5 & $2.06 @ 38.80$ b \\
\hline & $20^{\mathrm{a}}$ & $2.51 @ 38.76^{b}$ \\
\hline & 25 & $2.70 @ 38.75^{b}$ \\
\hline & 50 & $2.30 @ 38.89$ b \\
\hline & 5 & $0.02 @ 68.16$ \\
\hline & $20^{a}$ & $0.22 @ 68.17$ \\
\hline & 25 & $0.31 @ 68.17$ \\
\hline & 50 & $0.46 @ 68.18$ \\
\hline
\end{tabular}

${ }^{\mathrm{a}}$ Estimated; ${ }^{\mathrm{b}}$ These measured amplitudes are not relevant.

It has been shown that ultrasonic vibration results in increased evaporation rate in the liquid films [50]. To gain insight on this effect, we measured the wet film temperature and surface temperature of the substrates and vibrating steel boxes at varying frequency and power at $\sim 10 \mathrm{~s}$ from the actuation 
of the transducer. Due to the small rate of the evaporation process, the wet film is in thermodynamic equilibrium with its substrate, and there is negligible temperature difference along the depth of the film. Therefore, even though the infrared camera is not precisely pointing to the surface of the wet film, the measured temperature is the temperature of the wet film. The data are shown in Table S1 of the supporting information and correspond to an initial room temperature/steel box temperature of $\sim 22^{\circ} \mathrm{C}$, when the transducer is off. We observe that the wet films have the lowest temperature $\left(1^{\circ}-2^{\circ}\right.$ less than the substrate temperature), due to evaporative cooling of the wet films. Similarly, the surfaces of the dry substrates have a temperature of about $1^{\circ}-2^{\circ}$ less than those of the steel boxes, due to the conduction and contact resistance between the box and the substrate. With an increase in the vibration power, all temperatures rise, due to increased impartment of acoustic energy from the ultrasonic transducer to the steel box, substrate and wet film. Due to uncertainties, we cannot draw a conclusion on the effect of the vibration frequency on the temperatures. Nevertheless, it appears that at $68 \mathrm{kHz}$, the surface temperatures are lower than those at $40 \mathrm{kHz}$, which can be attributed to an increased impedance mismatch between the transducer and the steel box/substrate with an increase in the frequency. In other words, at a very high frequency, a larger portion of the acoustic waves are reflected back and, not absorbed by the steel box and the film. This also increases the chance of failure of the transducer due to overheating.

As mentioned earlier, in this work, we studied how placing a wet spun film of a solution on top of a vibrating steel box with a specific frequency and power will affect the film characteristics, in a process we call ultrasonic SVPT. In the rest of this paper, the film characteristics will be studied. The AFM height images and RMS roughness of pristine and SVPT PEDOT:PSS films are shown in Figures 3 and 4, respectively, for both glass/ITO and PET/ITO substrates. The corresponding phase images are shown in Figures S2 and S3 of the supporting information, revealing a fibrous morphology, but a clear phase segregation/separation is not observed. Therefore, we studied the possibility of phase separation using other methods, to be discussed later.

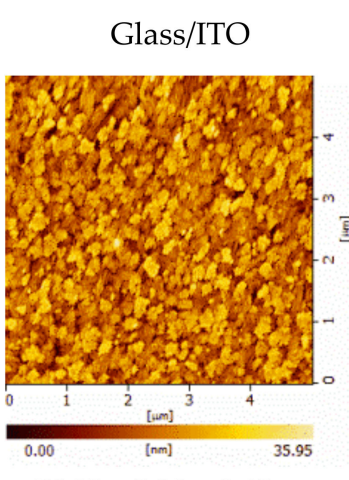

RMS $=5.83 \pm 0.15 \mathrm{~nm}$

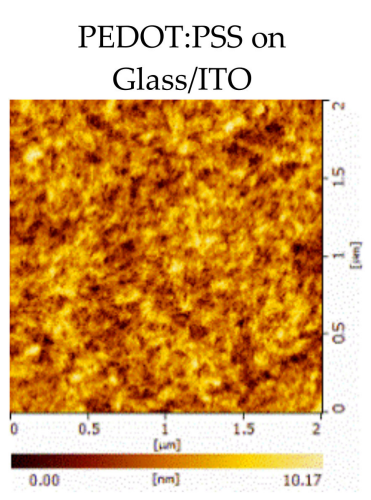

$2.0 \pm 0.08 \mathrm{~nm}$

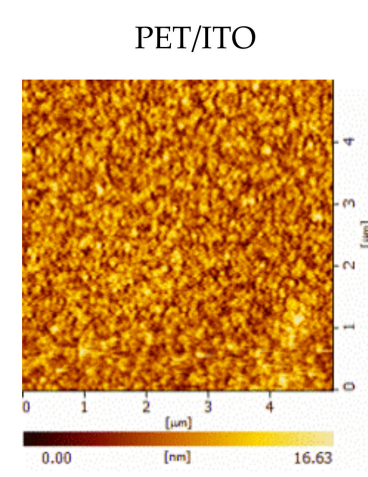

$3.32 \pm 0.53 \mathrm{~nm}$

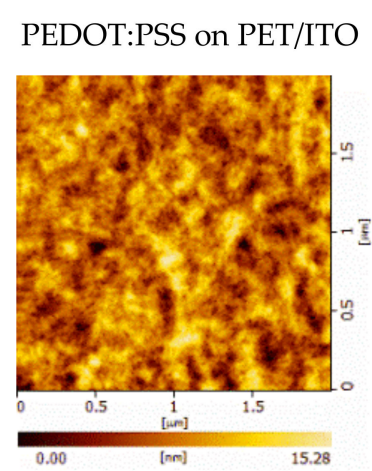

$2.6 \pm 0.26 \mathrm{~nm}$

Figure 3. AFM height images and RMS roughness of glass/ITO and PET/ITO substrates and the pristine PEDOT:PSS films, spun on those substrates. The corresponding phase images of PEDOT:PSS films are shown in Figure S2 of supporting information. 


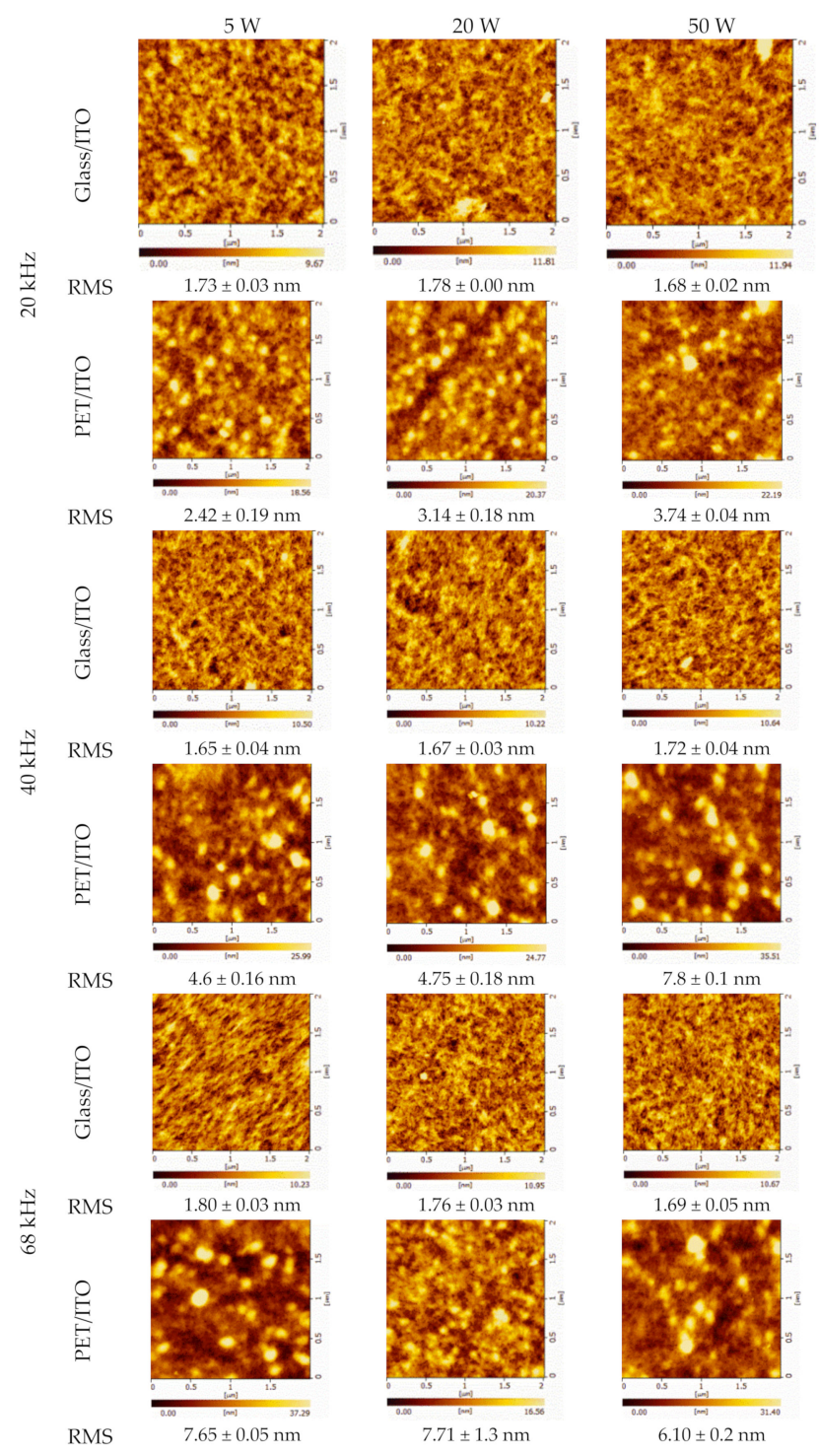

Figure 4. AFM height images showing the effect of varying vibration power and frequency on the film topography and RMS roughness of PEDOT:PSS films treated by the SVPT. This figure also studies the effect of using rigid (glass/ITO) and flexible plastic (PET/ITO) substrates on the film morphology and roughness. The corresponding phase images are shown in Figure S3 of supporting information.

Figures 3 and 4 reveal several observations about the effect of each variable on the film topography. The pristine and SVPT PEDOT:PSS films spun on PET/ITO show different morphology compared to the films spun on glass/ITO substrates. The SVPT PEDOT:PSS spun on glass/ITO show a fibrous structure, while a mixed fibrous/granular morphology appears on the SVPT films spun on the PET/ITO substrates, also supported by phase images (Figures S2 and S3). The granular morphology results in a significant increase in the roughness of the films spun on the PET/ITO substrates. The SEM images of PEDOT:PSS films are shown in Figures S4 and S5. The SVPT films show a smooth and uniform surface for coatings on glass/ITO substrates, whereas for the films spun on PET/ITO substrates, a granular surface has formed, consistent with the AFM height images. Although roughness of the glass/ITO substrate is higher than that of the PET/ITO substrate, as shown in Figure 3, the PEDOT:PSS spun on the former is smoother than that spun on the latter. This will be explained later in conjunction with the contact angle data. Figures 3 and 4 also reveal that the application of the SVPT on wet PEDOT:PSS spun on glass/ITO substrates results in a decrease in roughness from about $2.0 \mathrm{~nm}$ to $1.65-1.8 \mathrm{~nm}$, depending on the power and frequency, which is at least a $10 \%$ decline in roughness. We deduce that 
ultrasonic vibration tends to homogenize the solution and level the surface, before it is dried. Varying the vibration power or frequency does not show a conclusive trend, for the range of the parameters studied here. We attribute this to the difficulty to transmit the acoustic waves from the ultrasonic transducer to the films, in an exactly consistent manner in order to maintain an identical impedance mismatch. This impedance mismatch argument applies to the flexible substrates, in a larger extent. We found that the effect of ultrasonic vibration is quite different for the films spun on flexible PET/ITO substrates. SVPT applied on PEDOT:PSS film at $20 \mathrm{kHz}$ and $5 \mathrm{~W}$ results in a significant decrease in roughness from $3.32 \mathrm{~nm}$ down to $2.42 \mathrm{~nm}$. However, for other increased vibration powers and frequencies (except for $20 \mathrm{kHz}$ and $20 \mathrm{~W}$ ), the roughness is larger than that of the pristine film. The AFM phase images of Figures S2 and S3 for the PEDOT:PSS films spun on flexible PET/ITO substrates show some large grains indicating some degree of segregation. In summary, we conclude that the SVPT results in a decrease in the film roughness in all powers and frequencies when a rigid substrate is used, whereas in the case of a flexible substrate, the roughness may increase or decrease. Application of flexible ultrasonic transducers, such as polymeric piezoelectric materials (piezopolymers), may result in better linkage and impedance matching between the polymer transducer and the flexible substrates.

In the next step, we studied the variation of the film thickness with vibration frequency and power. Figure 5 a shows that with the application of ultrasonic vibration $(5 \mathrm{~W})$, the film thickness decreases for the films spun on both glass/ITO and PET/ITO substrates. Frequencies of 20 and $40 \mathrm{kHz}$ have a comparable effect on the thickness; however, with further increase of the frequency to $68 \mathrm{kHz}$ at constant power of $5 \mathrm{~W}$, thickness increases again, because of the small amplitude at this high frequency (c.f., Table 1). At power of $5 \mathrm{~W}$ and frequency of $40 \mathrm{kHz}$, the lowest thickness was achieved for PEDOT:PSS spun on both glass/ITO $(48 \mathrm{~nm})$ and PET/ITO $(71 \mathrm{~nm})$ substrates. The effect of varying the vibration power on film thickness is inconclusive, due to the large error bars originated from approximate nature of thickness measurements at such small thicknesses [24]. Nevertheless, a qualitative decreasing trend in the film thickness and thus in the film compactness is observed in most cases, especially those coated on rigid glass substrates.

Interestingly, the pristine film spun on flexible PET/ITO substrate is considerably thicker than the film spun on the rigid glass/ITO substrate. This can be attributed to the surface characteristics of the substrates, such as roughness, friction, surface energy (wettability) and contact angle of PEDOT:PSS solution droplets on each substrate. As discussed above and shown in Figure 3, roughness of the glass/ITO surface is $5.83 \mathrm{~nm}$ compared to $3.32 \mathrm{~nm}$ for the PET/ITO surface. Since the roughness of glass/ITO is higher than that of the PET/ITO, one may expect that the PEDOT:PSS film deposited on the former to be thicker than that deposited on the latter, because of the hydrodynamics of spin coating [23], in that a higher surface friction would decelerate the radial flow, thus leading to the formation of a thicker film. However, when we consider the surface science and its effect on the film thickness, we will be able to understand and interpret the data. The contact angle of PEDOT:PSS solution droplet on glass/ITO and PET/ITO substrates were measured to be $9.6^{\circ} \pm 0.4^{\circ}$ and $12.55^{\circ} \pm 0.55^{\circ}$, respectively. This difference may be due to the brief surface treatment (washing and UV treatment) that we applied to PET/ITO substrates to avoid damaging of the ITO. The smaller the contact angle, the higher the surface energy and consequently, the higher the surface wettability. Thus, the formation of smoother (Figures 3 and 4) and thinner films (Figure 5) on glass/ITO may be attributed to higher wettability of glass/ITO compared to PET/ITO. 

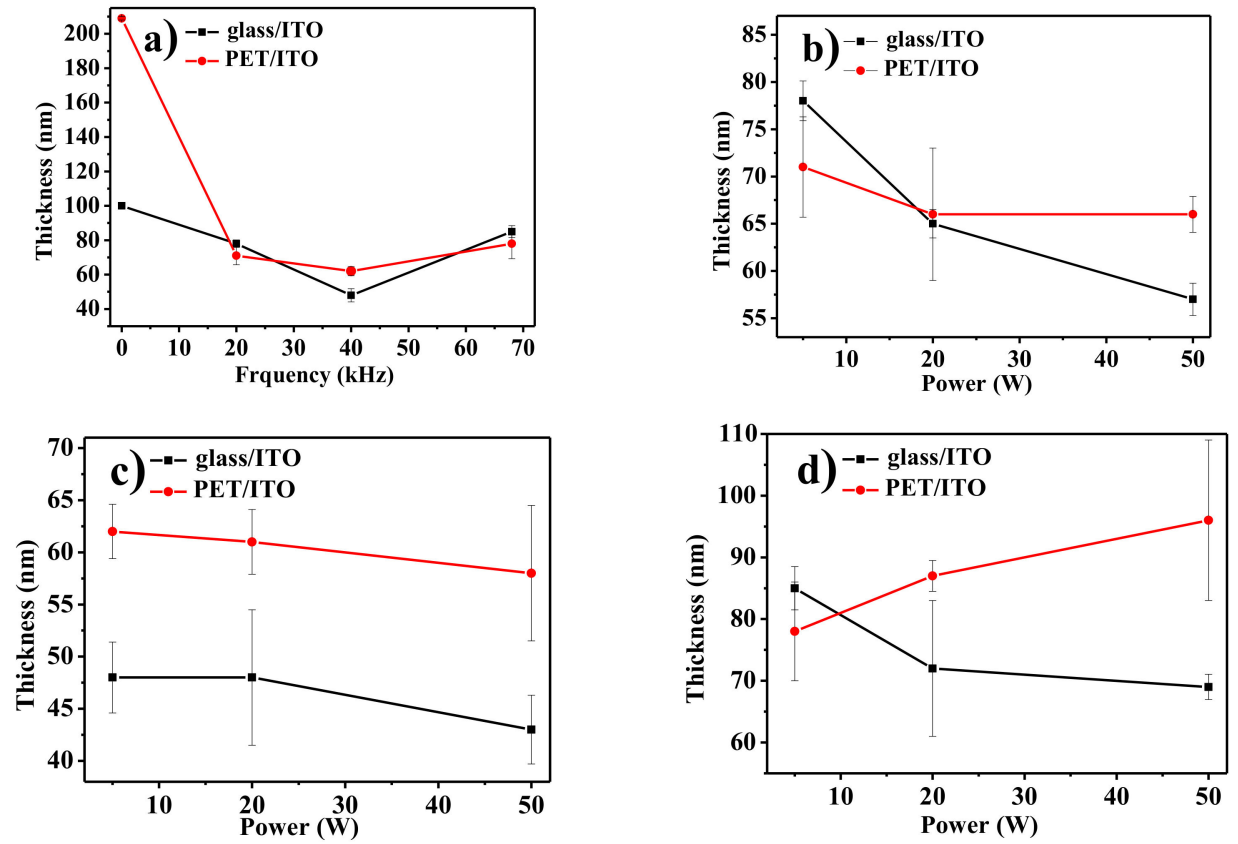

Figure 5. Thickness of PEDOT:PSS coated on glass/ITO and PET/ITO substrates at varying frequencies and powers. (a) Thickness versus frequency at $5 \mathrm{~W}$, and thickness versus power at (b) $20 \mathrm{kHz}$, (c) $40 \mathrm{kHz}$, and (d) $68 \mathrm{kHz}$, respectively.

Figure 6 shows the transmittance of pristine and SVPT (vibrated) PEDOT:PSS films at three frequencies and input power of $5 \mathrm{~W}$. Figure $\mathrm{S} 6$ shows the broadband transmittance spectra of the same films. SVPT PEDOT:PSS coated on glass/ITO shows a slight improvement in transmittance at low wavelengths. In contrast, there is a small decrease in the transmittance of SVPT PEDOT:PSS coated on PET/ITO near the peak. Overall, it is concluded that film treatment by the ultrasonic vibration does not significantly affect the transmittance of the PEDOT:PSS films.
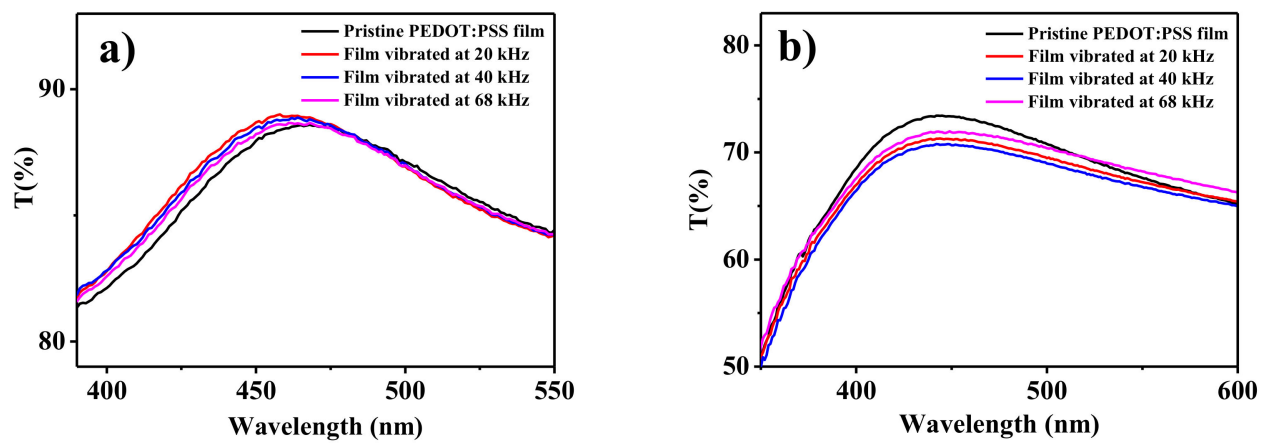

Figure 6. Transmittance of the pristine and vibrated (SVPT) PEDOT:PSS films deposited on (a) glass/ITO and (b) PET/ITO substrates. The power of vibration is $5 \mathrm{~W}$ and the background is air.

An important characteristics of PEDOT:PSS thin film is its sheet resistance (thickness dependent) and electrical conductivity (thickness independent). Table S2 lists the sheet resistance (Rs) of PEDOT:PSS coated on glass/ITO and PET/ITO substrates at various ultrasonic vibration frequencies and powers. We observe that by applying the SVPT, Rs has decreased, substantially. The variation of electrical conductivity of PEDOT:PSS films with ultrasonic frequency and power are displayed in Figure 7. Several key observations can be made, as follows. First, the electrical conductivity significantly increases with the application of the SVPT, where a five-fold increase is observed at $40 \mathrm{kHz}$ (Figure $7 \mathrm{a}$ at $5 \mathrm{~W}$ ). At vibration frequencies of 20 and $40 \mathrm{kHz}$, the conductivity increases with the vibration power, whereas at frequency of $68 \mathrm{kHz}$, the conductivity appears to be insensitive to the 
vibration power, supposedly because at high frequencies the acoustic impedance mismatch between the transducer and the substrate increases. In other words, at high frequency, the acoustic waves will be reflected and not absorbed by the film. The highest conductivity is achieved at $40 \mathrm{kHz}$ and $50 \mathrm{~W}$ (more than six-fold increase compared to the pristine film). The conductivity response of PEDOT:PSS deposited on both rigid and flexible substrates is similar. As it is understood, PEDOT:PSS has a core/shell structure (coil conformation) in water in which insulating hydrophilic PSS is the shell and conducting hydrophobic PEDOT is within the core, where the PEDOT chains are stabilized by PSS, due to the Columbic electrostatic interaction between PEDOT and PSS segments $[27,51]$. We believe that the acoustic radiation forces and flow microstreaming induced in the solution due to ultrasonic vibration of the substrate result in rearrangement of the PEDOT and PSS orientation and even detachment of PSS from PEDOT. Also, by applying ultrasonic vibration, the PEDOT chains can further turn into extended-coil, stretched, fibrous or linear conformation, as tentatively confirmed by a decrease in thickness of the SVPT PEDOT:PSS thin films. Thus, we attribute the improvement in the electrical conductivity to phase separation (exposure of PEDOT, which is conductive) and better orientation and stretching of PEDOT-rich grains on the surface, leading to the formation of conducting pathways for transfer of charge carriers. We will further investigate phase separation in the following sections using XPS, FTIR, and contact angle data of water droplets on PEDOT:PSS coatings.
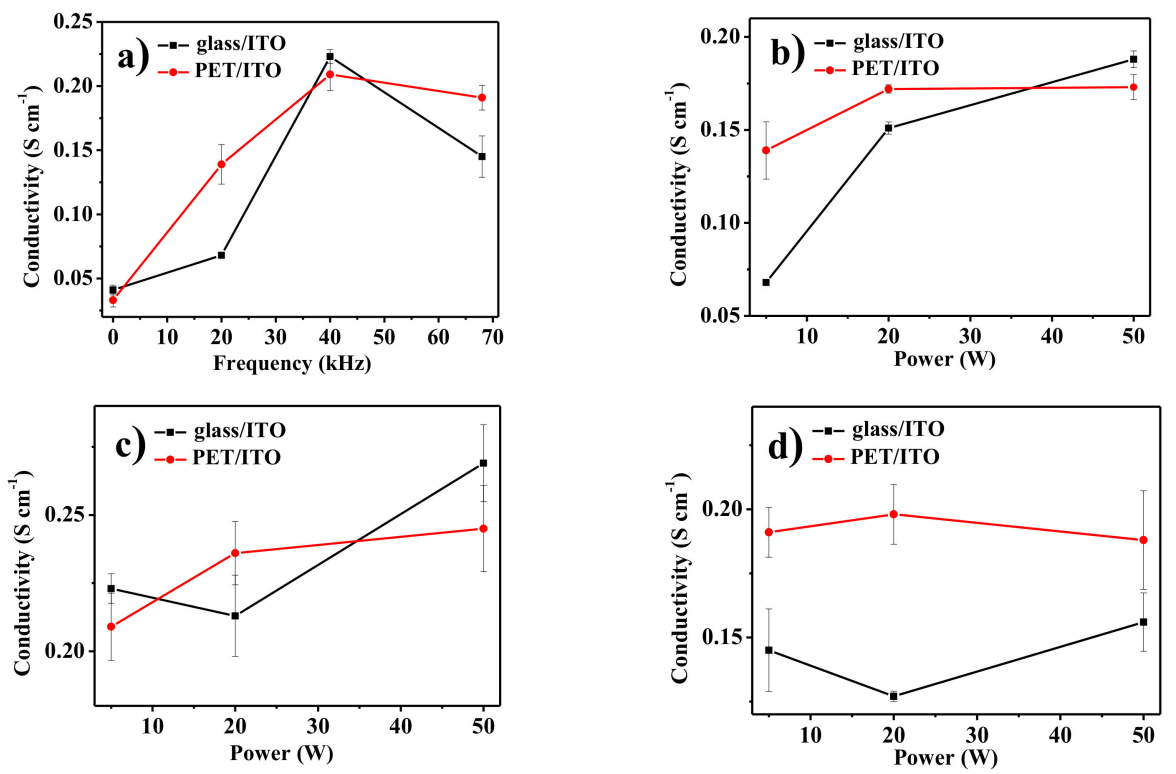

Figure 7. Conductivity of PEDOT:PSS coated on glass/ITO and PET/ITO substrates at varying frequencies and powers of vibration. (a) Conductivity versus frequency at $5 \mathrm{~W}$, and conductivity versus power at (b) $20 \mathrm{kHz}$, (c) $40 \mathrm{kHz}$, and (d) $68 \mathrm{kHz}$, respectively.

The surface chemical compositions of the films were analysed by XPS to understand the effect of the vibration on binding energy and possible phase separation of PEDOT:PSS. Figure 8 reveals the XPS spectra of the PEDOT:PSS films without and with vibration at power of $5 \mathrm{~W}$. The measurements were repeated multiple times in two different equipment and same results were reproduced. Since the sulphur (S) atom of thiophene in PEDOT and of sulfonate in PSS segments have different binding energies, there are two characteristic sulphur $2 p(\mathrm{~S} 2 \mathrm{p})$ peaks: the peaks at higher binding energy between (169-172 eV) correspond to the sulphur in PSS, while the peaks at the lower binding energy between (164-166 eV) correspond to the sulphur atom in PEDOT [52-55]. Figure 8a reveals that for the films deposited on glass/ITO, the S2p peak intensity, at both lower and higher energies, has decreased with vibration. The mass ratio of PSS to PEDOT can be estimated by calculating the integral areas under the peaks assigned to PSS and PEDOT for the vibrated films, at each frequency. By applying vibration, the ratio of PSS to PEDOT for the films on glass/ITO decreased from 2.61 for pristine film to 
$2.55,2.55$ and 2.54, for the vibrated films at 20, 40 and $68 \mathrm{kHz}$, respectively, suggesting the removal of PSS from the surface of PEDOT:PSS grains. This finding, at least qualitatively, is in favor of our argument that improvement in the conductivity of vibrated PEDOT:PSS films is due to the reduction of insulating PSS and increase of the presence of PEDOT-rich domains on the surface (the layer near the surface that emits XPS electrons). The calculation of integral areas under the S2p peaks represents that the mass ratio of PSS to PEDOT did not change with applying vibration for the films deposited on PET/ITO (Figure 8b). Additional and more in-depth studies are needed to explain the complex XPS phenomena, such as a shift in binding energy due to ultrasonic vibration.
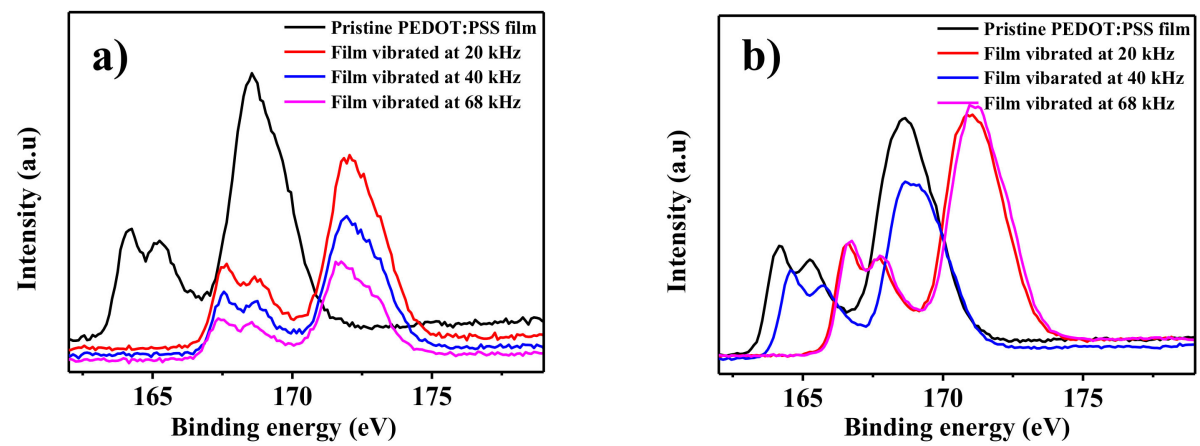

Figure 8. Sulphur $2 \mathrm{p}$ XPS spectra of the pristine and vibrated (SVPT) PEDOT:PSS coated on (a) glass/ITO, and (b) PET/ITO substrates. The vibration power is $5 \mathrm{~W}$.

We also performed ATR-FTIR tests on the PEDOT:PSS films at power of $5 \mathrm{~W}$ (Figure 9). Interestingly, we realized that in some parts of the films the FTIR spectra look different compared to the FTIR of pristine PEDOT:PSS. It is evident that sharper peaks have appeared in the spectra of the films that were subjected to vibration. Generally, during polymerization of 3,4-ethylenedioxythiophene (EDOT), monomer to PEDOT, free $\alpha$ and $\alpha$ positions of EDOT are involved (Figure 10). Importantly, the appearance of the peaks at $840 \mathrm{~cm}^{-1}$ for the films deposited on glass/ITO and $870 \mathrm{~cm}^{-1}$ for the films deposited on PET/ITO [56,57], which is ascribed to C-H bending mode in EDOT, demonstrates possible breaking of some of the polymer chains in the film after treatment with vibration. Moreover, there is a possibility that PSS chains are also broken as a result of vibration, but the related peaks at wavenumbers smaller than $1000 \mathrm{~cm}^{-1}$ might have overlapped with those of PEDOT. Therefore, vibration, as a mechanical force, may give rise to breakup of some of the polymer chains of PEDOT:PSS to its oligomers. As the length of a conjugated polymer (here PEDOT) decreases, electrons resonate at higher energies due to the enhanced energy level between the highest occupied molecular orbital (HOMO) and lowest unoccupied molecular orbital (LUMO) [58].
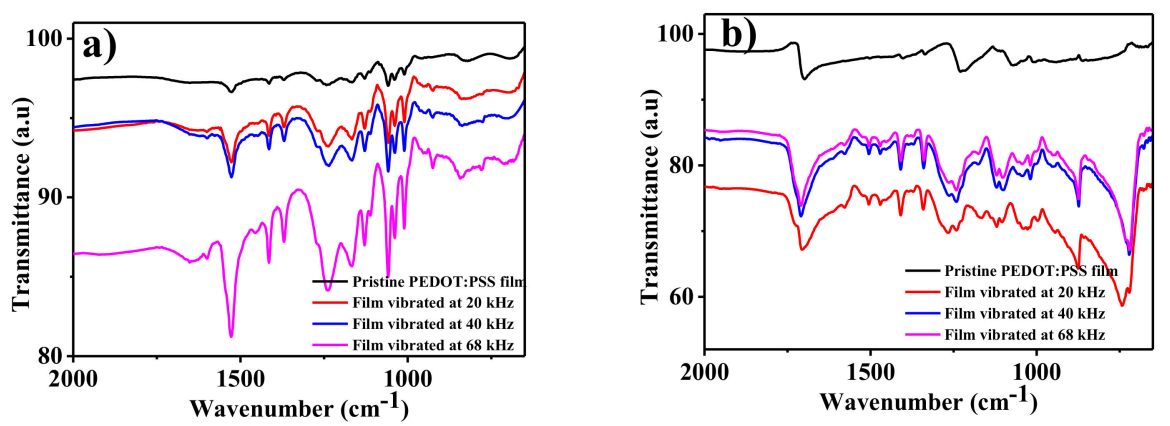

Figure 9. ATR-FTIR spectra of PEDOT:PSS films deposited on (a) glass/ITO and (b) on PET/ITO substrates. The vibration power is $5 \mathrm{~W}$. 
a)

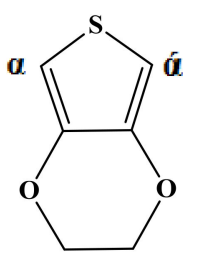

b)

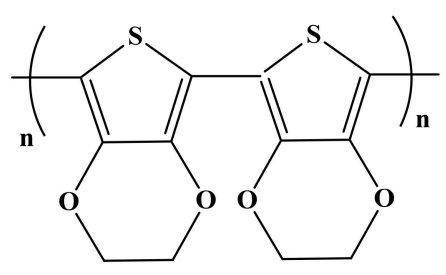

Figure 10. (a) $\alpha$ and $\alpha$ positions of EDOT are included during polymerization; (b) structure of PEDOT polymer.

In the previous sections, we attributed the increase in conductivity of SVPT samples to phase separation between hydrophobic PEDOT and hydrophilic PSS, and formation of more connected fibrous PEDOT chains to serve as charge pathways $[28,29]$. Our XPS and ATR-FTIR data were in favor of this argument. To further substantiate this claim, we measured the contact angles of water droplets on PEDOT:PSS coatings on glass/ITO and PET/ITO substrates, at three ultrasonic frequencies and input power of $5 \mathrm{~W}$ (Table 2). On the pristine PEDOT:PSS film, the average contact angles on glass / ITO and PET/ITO are $24.5^{\circ}$ and $22.3^{\circ}$, respectively, with moderate hysteresis. We observe a very significant increase in the contact angles of water on the PEDOT:PSS films that were subjected to the SVPT. The effect is stronger on the films deposited on glass/ITO ( three-fold increase), compared to PET/ITO ( two-fold increase). We attribute the increase in contact angle to two effects. First, in general, the vibration treatment imparts energy to the surface and will somewhat increase the surface energy, resulting in a decrease in contact angles. However, the very significant increase in the vibration-treated samples lead us to believe that vibration causes more hydrophobic PEDOT chains or PEDOT-rich grains to appear on the surface (causing an increase in contact angle), confirming the phase separation after treatment with vibration. A similar behavior, i.e., an increase in contact angle of water droplets on PEDOT:PSS coatings, has been reported when a PEDOT:PSS film was aged, where losses of PSS-chain occurred and left the PEDOT-chain exposed [59].

Table 2. Contact angle of water droplets on PEDOT:PSS films spun on glass/ITO and PET/ITO substrates. The diameter of the needle is $0.7 \mathrm{~mm}$, and can be regarded as the scale bar.

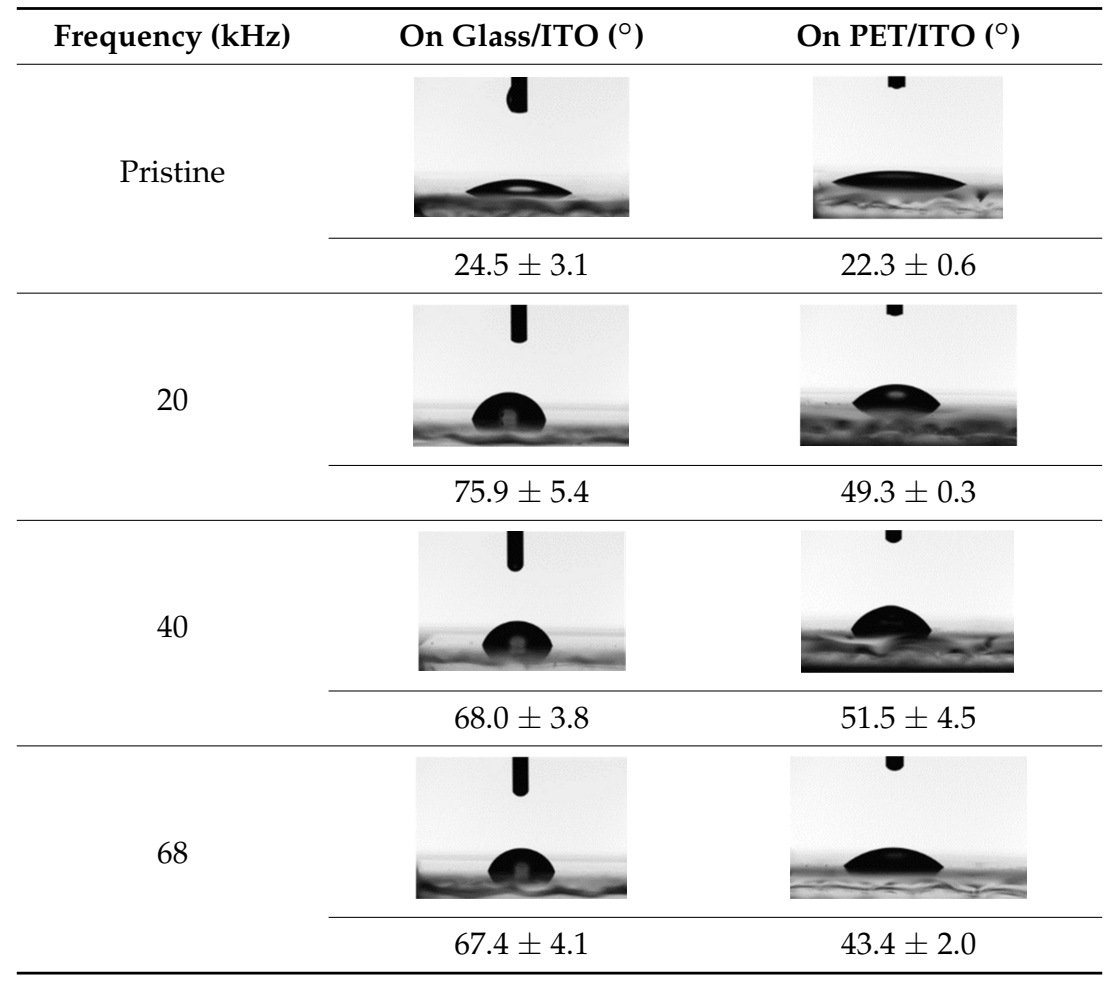


Our contact angle results also put forward a method for manipulating the surface energy, surface wetting and contact angle of water droplets on PEDOT:PSS coatings by imposing ultrasonic vibration. This effect may be observed and applicable to other coating materials, opening windows of opportunities for new applications.

Finally, in order to investigate the flexibility of the PEDOT:PSS films spun on PET/ITO substrates, a bending test was conducted. The sheet resistance of the films prepared at three vibration frequencies and power of $5 \mathrm{~W}$ were measured after each bending cycle (Figure 11). While the resistance changes after each cycle (increase or decrease), on average, no significant change in the sheet resistance is observed after 30 cycles, corroborating the merit of the PEDOT:PSS films deposited on flexible plastic substrates.

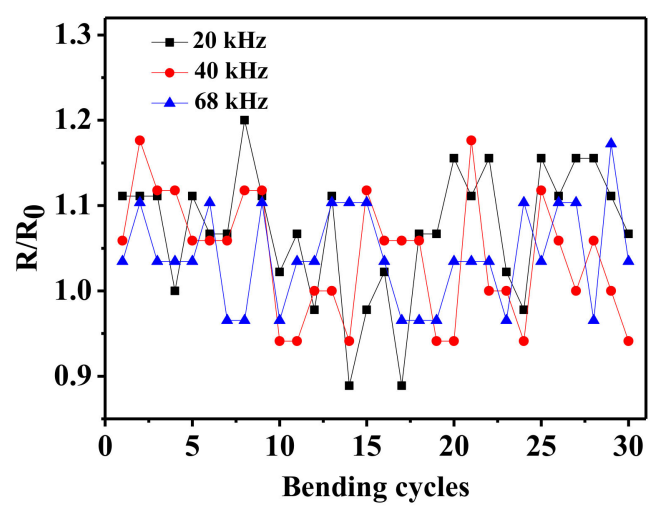

Figure 11. Normalized sheet resistance of the SVPT PEDOT:PSS films deposited on flexible PET/ITO substrates.

\section{Conclusions}

In this study, we investigated the influence of varying frequency $(20,40$, and $68 \mathrm{kHz})$ and power $(5,20$, and $50 \mathrm{~W})$ of ultrasonic vibration imposed on the wet PEDOT:PSS films, as a post treatment method. It is not a surprise to observe that literally all characteristics of the PEDOT:PSS films which were subjected to ultrasonic vibration changed, generally toward the positive direction. We draw some major conclusions as follows:

Detailed characterization of vertically vibrating steel boxes equipped with Langevin ultrasonic transducers showed that at $20 \mathrm{kHz}$, the maximum displacement is large $(300 \mathrm{~nm}$ at $5 \mathrm{~W}$ and $664 \mathrm{~nm}$ at $50 \mathrm{~W}$ ). At $40 \mathrm{kHz}$, the maximum displacement drops to $3.85 \mathrm{~nm}$ at $5 \mathrm{~W}$ and $7.84 \mathrm{~nm}$ at $50 \mathrm{~W}$. At $68 \mathrm{kHz}$, the maximum amplitude is less than $1 \mathrm{~nm}$. By performing acoustic calculations, we found that a portion of the transducer power transmits to the substrate and the rest is reflected, due to a mismatch between the impedance of the transducer, steel box, and the substrate. The impedance mismatch increases with frequency and it is higher for the plastic substrate compared to the glass substrate. Due to a high impedance mismatch at $68 \mathrm{kHz}$, this frequency is not suitable for the ultrasonic substrate vibration post treatment (SVPT).

Compared to the pristine spun films, the electrical conductivity of the films subjected to ultrasonic vibration significantly increased. The maximum increase is $\sim$ five-fold and is associated with a transducer frequency of $40 \mathrm{kHz}$ and power of $50 \mathrm{~W}$. To explain this phenomenon, various characterization tests revealed that PEDOT and PSS in fibrous PEDOT:PSS shells detach and the concentration of PEDOT, which is the conducting group in PEDOT:PSS, is higher on the surface, giving rise to an increase in the film conductivity. In addition, it was inferred that, beside detachment, the chains of PEDOT and PSS may break into smaller chains, due to excitation by ultrasonic vibration. With ultrasonic vibration, we also observed a decrease in the film thickness, and therefore an increase in the polymer film packing. In addition, we found that the contact angle of water droplet increases when the PEDOT:PSS film is treated with ultrasonic vibration. This effect can be exploited to prepare substrates with tailored wetting properties. 
The effect of the ultrasonic vibration on the PEDOT:PSS films deposited on PET/ITo substrates were nearly similar to those deposited on glass/ITO substrates, although some anomalies were observed, such as an increase in the film roughness. It appears that the flexible nature of the plastic substrates adds to the difficulty to prepare reproducible solution-processed films on such substrates. Nevertheless, the enhanced conductivity of PEDOT:PSS films and successful bending tests demonstrated that the ultrasonic vibration technique works well on flexible substrates, although further studies is entailed.

Supplementary Materials: The following are available online at http:/ / www.mdpi.com/2079-6412/8/10/337/ s1, Table S1: Temperatures $(T)$ of the wet film and surface of the dry substrate and the vibrating steel box during vibration, taken at room temperature $\left(\sim 22^{\circ} \mathrm{C}\right)$, Table S2: Sheet resistance $\left(R_{\mathrm{S}}\right)$ of PEDOT:PSS films spun on glass/ITO and PET/ITO substrates and treated at different frequencies and powers, Figure S1: Noise characterization of the base used during vibration analysis, Figure S2: AFM phase images of pristine PEDOT:PSS films, Figure S3: AFM phase images showing the effect of vibration power and frequency on PEDOT:PSS films treated by the SVPT, Figure S4: SEM images of pristine spun PEDOT:PSS thin films, Figure S5: SEM images showing the effect of vibration power and frequency on the film topography of PEDOT:PSS films treated by the SVPT, Figure S6: Broadband transmittance of the pristine and vibrated (SVPT) PEDOT:PSS films deposited on (a) glass/ITO and (b) PET/ITO substrates.

Author Contributions: Conceptualization, M.E.; Methodology, N.G., D.B., M.E.; Formal Analysis, N.G., D.B.; Investigation, N.G., D.B.; Resources, N.G.; Writing-Original Draft Preparation, N.G.; Writing-Review \& Editing, M.E., N.G.; Supervision, M.E.; Project Administration, N.G.; Funding Acquisition, M.E.

Funding: This research was funded by the Shanghai Municipal Education Commission via the Oriental Scholar fund and the funding form the National Natural Science Foundation of China (NSFC).

Conflicts of Interest: The authors declare no conflict of interest.

\section{References}

1. Eslamian, M. Inorganic and organic solution-processed thin film devices. Nano-Micro Lett. 2017, 9, 3. [CrossRef]

2. Skotheim, T.A.; Reynolds, J. Conjugated Polymers: Theory, Synthesis, Properties, and Characterization; CRC Press: Boca Raton, FL, USA, 2006.

3. Das, T.K.; Prusty, S. Review on conducting polymers and their applications. Polym. Plast. Technol. Eng. 2012, 51, 1487-1500. [CrossRef]

4. Shirakawa, H.; Louis, E.J.; MacDiarmid, A.G.; Chiang, C.K.; Heeger, A.J. Synthesis of electrically conducting organic polymers: Halogen derivatives of polyacetylene, $(\mathrm{CH})_{x}$. J. Chem. Soci. Chem. Commun. 1977, 16, 578-580. [CrossRef]

5. Sun, K.; Zhang, S.; Li, P.; Xia, Y.; Zhang, X.; Du, D.; Isikgor, F.H.; Ouyang, J. Review on application of PEDOTs and PEDOT: PSS in energy conversion and storage devices. J. Mater. Sci. Mater. Electron. 2015, 26, 4438-4462. [CrossRef]

6. Groenendaal, L.; Jonas, F.; Freitag, D.; Pielartzik, H.; Reynolds, J.R. Poly(3,4-ethylenedioxythiophene) and its derivatives: Past, present, and future. Adv. Mater. 2000, 12, 481-494. [CrossRef]

7. Weickert, J.; Sun, H.; Palumbiny, C.; Hesse, H.C.; Schmidt-Mende, L. Spray-deposited PEDOT:PSS for inverted organic solar cells. Sol. Energy Mater. Sol. Cells 2010, 94, 2371-2374. [CrossRef]

8. Kim, Y.; Lee, J.; Kang, H.; Kim, G.; Kim, N.; Lee, K. Controlled electro-spray deposition of highly conductive PEDOT: PSS films. Sol. Energy Mater. Sol. Cells 2012, 98, 39-45. [CrossRef]

9. You, J.; Dou, L.; Hong, Z.; Li, G.; Yang, Y. Recent trends in polymer tandem solar cells research. Prog. Polym. Sci. 2013, 38, 1909-1928. [CrossRef]

10. Duraisamy, N.; Muhammad, N.M.; Ali, A.; Jo, J.; Choi, K.-H. Characterization of poly(3,4-ethylenedioxythiophene): poly(styrenesulfonate) thin film deposited through electrohydrodynamic atomization technique. Mater. Lett. 2012, 83, 80-83. [CrossRef]

11. Lang, U.; Müller, E.; Naujoks, N.; Dual, J. Microscopical investigations of PEDOT:PSS thin films. Adv. Funct. Mater. 2009, 19, 1215-1220. [CrossRef]

12. Jönsson, S.; Birgerson, J.; Crispin, X.; Greczynski, G.; Osikowicz, W.; Van Der Gon, A.D.; Salaneck, W.R.; Fahlman, M. The effects of solvents on the morphology and sheet resistance in poly(3,4-ethylenedioxythiophene)polystyrenesulfonic acid (PEDOT-PSS) films. Synth. Met. 2003, 139, 1-10. [CrossRef] 
13. Medford, A.J.; Lilliedal, M.R.; Jørgensen, M.; Aarø, D.; Pakalski, H.; Fyenbo, J.; Krebs, F.C. Grid-connected polymer solar panels: Initial considerations of cost, lifetime, and practicality. Opt. Express 2010, 18, A272-A285. [CrossRef] [PubMed]

14. Krebs, F.C.; Gevorgyan, S.A.; Alstrup, J. A roll-to-roll process to flexible polymer solar cells: Model studies, manufacture and operational stability studies. J. Mater. Chem. 2009, 19, 5442-5451. [CrossRef]

15. Krebs, F.C.; Tromholt, T.; Jørgensen, M. Upscaling of polymer solar cell fabrication using full roll-to-roll processing. Nanoscale 2010, 2, 873-886. [CrossRef] [PubMed]

16. Kirchmeyer, S.; Reuter, K. Scientific importance, properties and growing applications of poly(3,4-ethylenedioxythiophene). J. Mater. Chem. 2005, 15, 2077-2088. [CrossRef]

17. Kemerink, M.; Timpanaro, S.; De Kok, M.; Meulenkamp, E.; Touwslager, F. Three-dimensional inhomogeneities in PEDOT: PSS films. J. Phys. Chem. B 2004, 108, 18820-18825. [CrossRef]

18. Xia, Y.; Ouyang, J. PEDOT: PSS films with significantly enhanced conductivities induced by preferential solvation with cosolvents and their application in polymer photovoltaic cells. J. Mater. Chem. 2011, 21, 4927-4936. [CrossRef]

19. Cho, S.; Lee, K. Heat-treatment-induced enhancement in the optical spectra of poly(3,4-ethylenedioxythiophene)/poly(stylenesulfonate) films. J. Korean Phys. Soc. 2005, 46, 973-976.

20. Schmidt, M.; Falco, A.; Loch, M.; Lugli, P.; Scarpa, G. Spray coated indium-tin-oxide-free organic photodiodes with PEDOT: PSS anodes. AIP Adv. 2014, 4, 107132. [CrossRef]

21. Tait, J.G.; Worfolk, B.J.; Maloney, S.A.; Hauger, T.C.; Elias, A.L.; Buriak, J.M.; Harris, K.D. Spray coated high-conductivity PEDOT: PSS transparent electrodes for stretchable and mechanically robust organic solar cells. Sol. Energy Mater. Sol. Cells 2013, 110, 98-106. [CrossRef]

22. Cho, C.-K.; Hwang, W.-J.; Eun, K.; Choa, S.-H.; Na, S.-I.; Kim, H.-K. Mechanical flexibility of transparent PEDOT:PSS electrodes prepared by gravure printing for flexible organic solar cells. Sol. Energy Mater. Sol. Cells 2011, 95, 3269-3275. [CrossRef]

23. Zabihi, F.; Xie, Y.; Gao, S.; Eslamian, M. Morphology, conductivity, and wetting characteristics of PEDOT:PSS thin films deposited by spin and spray coating. Appl. Surf. Sci. 2015, 338, 163-177. [CrossRef]

24. Eslamian, M.; Newton, J.E. Spray-on PEDOT:PSS and P3HT:PCBM thin films for polymer solar cells. Coatings 2014, 4, 85-97. [CrossRef]

25. Krebs, F.C. Fabrication and processing of polymer solar cells: A review of printing and coating techniques. Sol. Energy Mater. Sol. Cells 2009, 93, 394-412. [CrossRef]

26. Kim, J.; Jung, J.; Lee, D.; Joo, J. Enhancement of electrical conductivity of poly(3,4-ethylenedioxythiophene)/ poly(4-styrenesulfonate) by a change of solvents. Synth. Met. 2002, 126, 311-316. [CrossRef]

27. Ouyang, J.; Chu, C.W.; Chen, F.C.; Xu, Q.; Yang, Y. High-conductivity poly(3,4-ethylenedioxythiophene): Poly(styrene sulfonate) film and its application in polymer optoelectronic devices. Adv. Funct. Mater. 2005, 15, 203-208. [CrossRef]

28. Nardes, A.M.; Janssen, R.A.; Kemerink, M. A morphological model for the solvent-enhanced conductivity of PEDOT: PSS thin films. Adv. Funct. Mater. 2008, 18, 865-871. [CrossRef]

29. Hu, Z.; Zhang, J.; Hao, Z.; Zhao, Y. Influence of doped PEDOT:PSS on the performance of polymer solar cells. Sol. Energy Mater. Sol. Cells 2011, 95, 2763-2767. [CrossRef]

30. Yu, Z.; Xia, Y.; Du, D.; Ouyang, J. PEDOT: PSS films with metallic conductivity through a treatment with common organic solutions of organic salts and their application as a transparent electrode of polymer solar cells. ACS Appl. Mater. Interfaces 2016, 8, 11629-11638. [CrossRef] [PubMed]

31. Fan, Z.; Du, D.; Yu, Z.; Li, P.; Xia, Y.; Ouyang, J. Significant enhancement in the thermoelectric properties of PEDOT:PSS films through a treatment with organic solutions of inorganic salts. ACS Appl. Mater. Interfaces 2016, 8, 23204-23211. [CrossRef] [PubMed]

32. Wang, Q.; Ahmadian-Yazdi, M.-R.; Eslamian, M. Investigation of morphology and physical properties of modified PEDOT:PSS films made via in-situ grafting method. Synth. Met. 2015, 209, 521-527. [CrossRef]

33. Vosgueritchian, M.; Lipomi, D.J.; Bao, Z. Highly conductive and transparent PEDOT:PSS films with a fluorosurfactant for stretchable and flexible transparent electrodes. Adv. Funct. Mater. 2012, 22, 421-428. [CrossRef]

34. Döbbelin, M.; Marcilla, R.; Salsamendi, M.; Pozo-Gonzalo, C.; Carrasco, P.M.; Pomposo, J.A.; Mecerreyes, D. Influence of ionic liquids on the electrical conductivity and morphology of PEDOT:PSS films. Chem. Mater. 2007, 19, 2147-2149. [CrossRef] 
35. Murphy, R.J.; Weigandt, K.M.; Uhrig, D.; Alsayed, A.; Badre, C.; Hough, L.; Muthukumar, M. Scattering studies on poly(3,4-ethylenedioxythiophene)-polystyrenesulfonate in the presence of ionic liquids. Macromolecules 2015, 48, 8989-8997. [CrossRef]

36. Huang, L.; Cheng, X.; Yang, J.; Zhang, L.; Zhou, W.; Xiao, S.; Tan, L.; Chen, L.; Chen, Y. High-performance polymer solar cells realized by regulating the surface properties of PEDOT:PSS interlayer from ionic liquids. ACS Appl. Mater. Interfaces 2016, 8, 27018-27025. [CrossRef] [PubMed]

37. Badre, C.; Marquant, L.; Alsayed, A.M.; Hough, L.A. Highly conductive poly(3,4-ethylenedioxythiophene):poly(styrenesulfonate) films using 1-ethyl-3-methylimidazolium tetracyanoborate ionic liquid. Adv. Funct. Mater. 2012, 22, 2723-2727. [CrossRef]

38. Wang, Q.; Xie, Y.; Soltani-Kordshuli, F.; Eslamian, M. Progress in emerging solution-processed thin film solar cells-part I: Polymer solar cells. Renew. Sustain. Energy Rev. 2016, 56, 347-361. [CrossRef]

39. Mengistie, D.A.; Ibrahem, M.A.; Wang, P.-C.; Chu, C.-W. Highly conductive PEDOT:PSS treated with formic acid for ITO-free polymer solar cells. ACS Appl. Mater. Interfaces 2014, 6, 2292-2299. [CrossRef] [PubMed]

40. Zabihi, F.; Eslamian, M. Substrate vibration-assisted spray coating (SVASC): Significant improvement in nano-structure, uniformity, and conductivity of PEDOT:PSS thin films for organic solar cells. J. Coat. Technol. Res. 2015, 12, 711-719. [CrossRef]

41. Wang, Q.; Eslamian, M. Improving uniformity and nanostructure of solution-processed thin films using ultrasonic substrate vibration post treatment (SVPT). Ultrasonics 2016, 67, 55-64. [CrossRef] [PubMed]

42. Xie, Y.; Zabihi, F.; Eslamian, M. Fabrication of highly reproducible polymer solar cells using ultrasonic substrate vibration posttreatment. J. Photonics Energy 2016, 6, 045502. [CrossRef]

43. Zabihi, F.; Ahmadian-Yazdi, M.-R.; Eslamian, M. Fundamental study on the fabrication of inverted planar perovskite solar cells using two-step sequential substrate vibration-assisted spray coating (2S-SVASC). Nanoscale Res. Lett. 2016, 11, 71. [CrossRef] [PubMed]

44. Habibi, M.; Eslamian, M.; Soltani-Kordshuli, F.; Zabihi, F. Controlled wetting/dewetting through substrate vibration-assisted spray coating (SVASC). J. Coat. Technol. Res. 2016, 13, 211-225. [CrossRef]

45. Soltani-kordshuli, F.; Zabihi, F.; Eslamian, M. Graphene-doped PEDOT:PSS nanocomposite thin films fabricated by conventional and substrate vibration-assisted spray coating (SVASC). Eng. Sci. Technol. Int. J. 2016, 19, 1216-1223. [CrossRef]

46. Chen, Q.; Zabihi, F.; Eslamian, M. Improved functionality of PEDOT: PSS thin films via graphene doping, fabricated by ultrasonic substrate vibration-assisted spray coating. Synth. Met. 2016, 222, 309-317. [CrossRef]

47. Eslamian, M. Excitation by acoustic vibration as an effective tool for improving the characteristics of the solution-processed coatings and thin films. Prog. Org. Coat. 2017, 113, 60-73. [CrossRef]

48. Fang, X.; Fan, Z.; Gu, Y.; Shi, J.; Chen, M.; Chen, X.; Qiu, S.; Zabihi, F.; Eslamian, M.; Chen, Q. A solution processable flexible transparent conductive graphene/PEDOT:PSS film fabricated by spin and blade coating. J. Shanghai Jiao Tong Univ. (Sci.) 2018, 23, 106-111. [CrossRef]

49. Cheeke, J.D.N. Fundamentals and Applications of Ultrasonic Waves, 2nd ed.; CRC Press: Boca Raton, FL, USA, 2016.

50. Rahimzadeh, A.; Eslamian, M. On evaporation of thin liquid films subjected to ultrasonic substrate vibration. Int. Commun. Heat Mass Transf. 2017, 83, 15-22. [CrossRef]

51. Ouyang, J. "Secondary doping" methods to significantly enhance the conductivity of PEDOT:PSS for its application as transparent electrode of optoelectronic devices. Displays 2013, 34, 423-436. [CrossRef]

52. Greczynski, G.; Kugler, T.; Keil, M.; Osikowicz, W.; Fahlman, M.; Salaneck, W.R. Photoelectron spectroscopy of thin films of PEDOT-PSS conjugated polymer blend: A mini-review and some new results. J. Electron. Spectrosc. Relat. Phenom. 2001, 121, 1-17. [CrossRef]

53. Hwang, J.; Amy, F.; Kahn, A. Spectroscopic study on sputtered PEDOT.PSS: Role of surface PSS layer. Org. Electron. 2006, 7, 387-396. [CrossRef]

54. Park, H.; Lee, S.H.; Kim, F.S.; Choi, H.H.; Cheong, I.W.; Kim, J.H. Enhanced thermoelectric properties of PEDOT:PSS nanofilms by a chemical dedoping process. J. Mater. Chem. A 2014, 2, 6532-6539. [CrossRef]

55. Lazzaroni, R.; Logdlund, M.; Stafstrom, S.; Salaneck, W.R. The poly-3-hegxylthiophene/NOPF 6 systems: A photoelectron spectroscopy study of electronic structural changes induced by the charge transfer in the solid state. Chem. Phys. 1990, 93, 4433.

56. Selvaganesh, S.V.; Mathiyarasu, J.; Phani, K.; Yegnaraman, V. Chemical synthesis of PEDOT-Au nanocomposite. Nanoscale Res. Lett. 2007, 2, 546. [CrossRef] 
57. Ouyang, L.; Wei, B.; Kuo, C.-c.; Pathak, S.; Farrell, B.; Martin, D.C. Enhanced PEDOT adhesion on solid substrates with electrografted P(EDOT-NH 2$)$. Sci. Adv. 2017, 3, e1600448. [CrossRef] [PubMed]

58. Abdelhamid, M.E.; O'Mullane, A.P.; Snook, G.A. Storing energy in plastics: A review on conducting polymers \& their role in electrochemical energy storage. Rsc Adv. 2015, 5, 11611-11626.

59. Duc, C.; Vlandas, A.; Malliaras, G.G.; Senez, V. Wettability of PEDOT:PSS films. Soft Matter 2016, 12, 5146-5153. [CrossRef] [PubMed] 